Медико-профилактические технологии, обеспечивающие сохранение и приумножение здоровья детей под руководством медицинского персонала детского сада в соответствии с медицинскими требованиями и нормами, с использованием медицинских средств.

Физкультурно-оздоровительные технологии, направленные на физическое развитие и укрепление здоровья ребенка: развитие физических качеств, двигательной активности и становление физической культуры дошкольников, закаливание, дыхательная гимнастика, массаж и самомассаж, профилактика плоскостопия и формирование правильной осанки, оздоровительные процедуры в водной среде (бассейне) и на тренажерах, воспитание привычки к повседневной физической активности и заботе о здоровье и реализация этих технологий, как правило, осуществляется специалистами по физическому воспитанию и воспитателями в условиях специально организованных форм оздоровительной работы.

Технологии обеспечения социально-психологического благополучия ребенка, обеспечивающие психическое и социальное здоровье дошкольника.

Технологии здоровьесбережения и здоровьеобогащения педагогов дошкольного образования, направленные на развитие культуры здоровья педагогов детского сада, в том числе культуры профессионального здоровья, развитие потребности к здоровому образу жизни [2].

В целом можно констатировать, что здоровьесберегающая технология - это система, объединяющая в себе широкий спектр психолого-педагогических и организационно-функциональных установок, предполагающих многовариантную компоновку методов, приемов, форм, образовательно-воспитательных средств и процедур, которые на практике обеспечивают интеграцию учащегося в подготовленную среду. Данная технологически организованная система ориентирована на вполне конкретный педагогический целевой результат - высокий уровень здоровья дошкольников и учащихся начальной школы, а также креативное взращивание культуры их здорового образа жизни.

$$
* * *
$$

1. Источник №1 Иванова С.С. Здоровьесберегающая среда в ДОУ как фактор внедрения ФГОС ДО // Теория и практика образования в современном мире: материалы VII Междунар. науч. конф. (г. СанктПетербург, июль 2015 г.). - СПб.: Свое издательство, 2015. - С. 14-16.

2. Источник №2 Крылова М.А. Анализ современных здоровьесберегающих технологий в дошкольном образовании // Научное сообщество студентов ХХІ столетия. ГУМАНИТАРНЫЕ НАУКИ: сб. ст. по мат. XLIV междунар. студ. науч.-практ. конф. № 7(44). [электронный ресурс] - Режим доступа. - URL: https://sibac.info/archive/guman/7(44).pdf

3. Источник №3 Тюшникова А.Г. Повышение качества образования через использование здоровьесберегающих технологий // Научно-методический электронный журнал «Концепт». 2013. Т. 3. - C. $3236-3240$.

\title{
Саморокова C.A. \\ К актуальности проблемы управления методической работой педагогов в современной детской школе искусств средствами мониторинга
}

Нижневартовский государственный университет (Россия, Нижневартовск)

doi: $10.18411 / l j-25-12-2017-43$

idsp: 000001:lj-25-12-2017-43

Аннотация

В статье на основе современных подходов в менеджменте предпринимается попытка изучения мониторинга как средства управления методической работой педагогов в детской школе искусств. Методическая работа рассматривается как систематическая 
деятельность педагогов, направленная на повышение профессионального мастерства. Автор затрагивает вопрос требований, предъявляемых к педагогу, относит объект, предмет и критерии оценивания к базовым элементам разработки системы мониторинга.

Ключевые слова: детская школа искусств; методическая работа; дополнительное образование детей; управление методической работой педагогов; мониторинг.

Обновление содержания дополнительного образования, новые концепции в организации образовательной и досуговой деятельности, вариативность, дифференциация в работе с детьми, внедрение информационных и инновационных педагогических технологий как важного фактора развития образовательной организации, существенно влияют на содержание и организацию труда современного педагога. В условиях модернизации отечественного дополнительного образования детей, в числе актуальных вопросов выступает проблема развития системы детских школ искусств и распространения эффективных моделей педагогических и управленческих практик. Не случайно этому была посвящена Всероссийская научно-практическая конференция «Детская школа искусств - 2016: образование, управление, развитие», проведенная в рамках V Санкт-Петербургского международного культурного форума.

В создании и развитии условий для разработки системы учебно-методического обеспечения образовательного процесса в детских школах искусств как необходимого условия повышения качества образования большую роль играет система методической работы и эффективное управление ею. Одним из средств управления методической работой считается мониторинг, однако исследований не так много, поэтому актуальность разработки темы очевидна.

Методическая работа, как считают Е.В.Тихонова и Л.Г.Чепайкина - это систематическая коллективная и индивидуальная деятельность педагогических кадров, направленная на повышение их научно-теоретического, общекультурного уровня, психолого-педагогической подготовки и профессионального мастерства.

Детская школа искусств как учреждение дополнительного образования имеет свои специфические особенности, требующие специального внимания и изучения. В этой связи методическая работа в детской школе искусств нуждается в переосмыслении с учетом современного развития образовательного менеджмента. К педагогам дополнительного образования предъявляется широкий спектр требований: психосоматическое здоровье, профессиональная компетентность, умение работать с людьми и др. Оптимально, когда данные требования сочетаются с личностнопрофессиональными качествами преподавателя: рефлексией, эмпатией, способностью к межличностному общению, инициативностью, ответственностью, дисциплинированностью. С другой стороны педагоги школ искусств - это люди творческих профессий, равно как и работники умственного труда. Подбор кадров, их переподготовка, повышение квалификации, развитие мотивации становится одним из приоритетных направлений деятельности и развития школы. Следовательно, методическая работа выступает как стратегия, способная обеспечить решение ряда проблем: непрерывный профессиональный рост преподавателей в сочетании с тенденциями развития школы искусств и образовательными потребностями заказчиков; мониторинг текущих и итоговых результатов деятельности педагогов; их самообразование, освоение и внедрение инновационных и информационных технологий в образовательный процесс; развитие мотивации педагогических работников.

Очевидно, что методическая работа призвана оказывать реальную, действенную помощь педагогу в решении насущных педагогических задач, поэтому она не может протекать спонтанно и бессистемно. Постоянные обновления в системе образования требуют от педагогов, и от руководящего состава умелого проектирования оптимальной методической системы, обеспечивающей высокое качество образования. Важным 
средством в достижении этой цели выступает мониторинг, позволяющий оперативно выявлять изменения, происходящие в профессиональном развитии педагога. На основе полученных объективных данных упрощается задача принятия управленческих решений.

В ходе исследования нами выделены противоречия, делающие своевременным изучение вопросов мониторинга методической работы педагогов УДО в условиях реализации ФГОС. Это противоречия между:

- социальным заказом общества на выполнение дополнительным образованием функций, связанных с управлением методической работой педагогов в условиях реализации ФГОС и недостаточной готовностью образовательных структур к их реализации;

- потребностью педагогической практики в системном, объективном процессе мониторинга управлением методической работой педагогов УДО и отсутствием целостной, научно-обоснованной модели мониторинга.

В сфере образования термин «педагогический мониторинг» появился сравнительно недавно, наиболее часто используется, как подчеркивает О.П. Бурдакова, следующее определение: «Педагогический мониторинг»- это система организации сбора, хранения, обработки, распространения информации о деятельности педагогической системы, обеспечивающая непрерывное слежение за ее состоянием и прогнозированием её развития. Мониторинг проводится в целях аналитического обобщения результатов и корректировки деятельности всех участников образовательного процесса. Учет реальных факторов позволяет обеспечить оптимизацию деятельности образовательной организации. Мониторинг осуществляется в соответствии с действующими правилами и нормативными документами федерального и регионального уровней, программами деятельности и развития, оперативными планами работы, методическими материалами. К основным нормативным документам по педагогическому мониторингу относятся: Закон Российской Федерации от 29.12.2012 № 273-Ф3 «Об образовании в Российской Федерации»; Постановление Правительства Российской Федерации от 05.08.2013 № 662 «Об осуществлении мониторинга системы образования»; Приказ Министерства образования и науки Российской Федерации от 11.06.2014 № 657 «Об утверждении методики расчета показателей мониторинга системы образования»; Приказ Министерства образования и науки Российской Федерации от 15.01.2014 № 14 «Об утверждении показателей мониторинга системы образования».

Для системы дополнительного образования, в отличие от общеобразовательных учреждений, где существуют различные формы оценки качества образования (ЕГЭ, ГИА, контрольные и итоговые работы и т.д.), характерно: 1) отсутствие единых образовательных стандартов, в соответствии с которыми можно было бы проверить уровень развития детей в определённой деятельности, т.к. каждое учреждение дополнительного образования предоставляет свой перечень образовательных услуг с учётом запросов детей, потребностей семьи, особенностей социально-экономического развития региона и национально-культурных традиций; 2) отсутствие нормативноправовой базы, регламентирующей данный процесс.

Поэтому возникают трудности с оценкой качества образования в учреждении дополнительного образования, т.е. нужно определить: что оценивать? (каковы объекты); как это оценивать? (какова процедура, критерии оценки, шкалы и т.д); соответствуют ли образовательные результаты УДО потребностям и ожиданиям общества? (оценка соответствия образовательных результатов определённым, заранее спрогнозированным результатам).

Управление методической работой необходимо организовывать таким образом, чтобы через рефлексию, углубленное изучение проблем, проведение заседаний 
методобъединений, семинаров, методических и педагогических советов можно было точно представить состояние управляемой системы и складывающиеся тенденции. В процессе организации мониторинга могут возникать как объективные, так и субъективные проблемы, трудности. Для их преодоления необходимо учитывать следующие аспекты: подготовленность специалистов, качество и вариативность используемых методик, возможность совершенствования профессиональных умений педагогов. Эти факторы следует всегда учитывать и стремиться минимизировать негативные воздействия. Однако трудно создать эффективную систему мониторинга, так как каждая отдельная школа искусств осуществляет свою уникальную методическую работу. Это можно объяснить и отсутствием единых требований к результату работы методической службы учреждений дополнительного образования. Между тем, объект, предмет и критерии оценивания являются отправной точкой в создании системы методического мониторинга. Без их чёткой формулировки не возможен высокий уровень эффективности мониторинга. К тому же специфика мониторинга результатов педагогического процесса в рамках культуры и искусства часто проявляется в трудно диагностируемых явлениях, таких как музыкальная культура, художественное мышление, творческие способности и т.п.

Ответив на эти вопросы, мы сможем с уверенностью сказать, что образовательным процессом в УДО можно управлять (в сторону стабилизации или повышения его качества), а это является одной из задач деятельности современного руководителя образовательнойорганизации.

В процессе осуществления методической работы неизбежно приходится сталкиваться с проблемой обработки и систематизации получаемой информации, ведь педагогическая работа весьма многогранна, а результаты диагностики всегда обширны и требуют точной систематизации для дальнейшей работы, поэтому педагогический мониторинг становится ключевым средством методической работы в детской школе искусств, позволяет вывести работу с информацией на качественно новый уровень, упрощает диагностику, помогает структурировать и систематизировать полученные данные, что, в конечном счёте, способствует положительной динамике в профессиональном росте педагогов.

$$
* * *
$$

1. Бурдакова О.П. Мониторинг как механизм управления качеством образования // Управление качеством образования. 2007. № 3. С.53-69.

2. Буркова Р. Р. Управление методической работой в школе на основе праксеологического подхода // Научно-методический электронный журнал «Концепт». 2017. Т. 29. С. 40-44. Cм.: URL: http://ekoncept.ru/2017/770809.htm (дата обращения-11 декабря 2017 г.).

3. Всероссийская научно-практическая конференция «Детская школа искусств - 2016: образование, управление, развитие» // http://dshi8.chel.muzkult.ru/news_article/2105381/ (дата обращения-11 декабря 2017 г.).

4. Зворская Н.А. Повышение качества образования в детских школах искусств как приоритетное направление реализации концепции развития дополнительного образования детей // Управление современной детской школой искусств: опыт, проблемы, перспективы. Сборник материалов VIII Всероссийской научно-практической конференции в области художественного образования детей «АРТ-ЕКАТЕРИНБУРГ» (с международным участием) / Сост.: Воинкова Т.Е., Перевышина Н.Ю. Екатеринбург, 2015. С. 35-41.

5. Самовик О.А. Детские музыкальные школы и детские школы искусств в системе современного модернизирующегося музыкального образования// Вестник адыгейского государственного университета. Серия 3: педагогика и психология. 2013.№ 2 (117). С. 62-67.

6. Терентьева М.А. Управление учебно-методическим обеспечением - основа инновационной активности современной детской школой искусств // Лучшая научная статья 2017.Сборник статей победителей VII международного научно-практического конкурса. Пенза: Наука и просвещение, 2017. С. 184-188.

7. Тихонова Е.В., Чепайкина Л.Г.Теория и практика управления детской школой искусств. Екатеринбург: Урал.гос. пед. ун-т., 2011. 115 с. 